\title{
Correction to: Culture-dependent to culture-independent approaches for the bioremediation of paints: a review
}

\author{
A. H. Phulpoto ${ }^{1,2} \cdot$ M. A. Maitlo ${ }^{1}$ N. A. Kanhar ${ }^{1}$ \\ Published online: 13 July 2020 \\ (c) Islamic Azad University (IAU) 2020

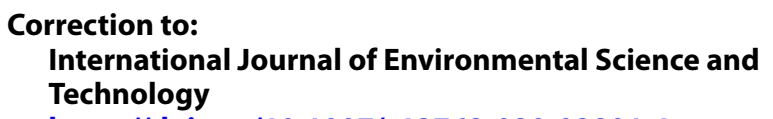

The article "Culture-dependent to culture-independent approaches for the bioremediation of paints: a review", written by A. H. Phulpoto - M. A. Maitlo · N. A. Kanhar, was originally published electronically on the publisher's internet portal (currently SpringerLink) on 20 June 2020 with open access. With the author(s)' decision to step back from Open Choice, the copyright of the article changed on July 2020 to (C) Islamic Azad University (IAU) 2020, part of Springer Nature 2020, and the article is forthwith distributed under the terms of copyright.

The original article can be found online at https://doi.org/10.1007/ s13762-020-02801-1.

N. A. Kanhar

nisar.kanhar@salu.edu.pk

1 Institute of Microbiology, Faculty of Natural Science, Shah Abdul Latif University Khairpur Mir's, Khairpur 66020,

Sindh, Pakistan

2 Sukkur Institute of Health Sciences, Sukkur 65200, Pakistan 